\title{
KNOWLEDGE REGARDING BREAST CANCER AND BREAST SELF EXAMINATION AMONG FEMALES
}

\author{
Ms. Leena Mathew(Sr. Gladys Maria)* | Dr. Bimla Rani** \\ * Research Scholar, Himalayan University, Itanagar, Arunachal Pradesh \& Asst. Professor, St. John's College of Nursing, Idukki, Kerala, India \\ ** Research Supervisor, Himalayan University, Itanagar, Arunachal Pradesh, India \\ DOI: http://doi.org/10.47211/idcij.2021.v08i03.007
}

\begin{abstract}
Background: Breast cancer is one of the most frequent cancers among the women. It can be detected earlier and survival rate can be improved by screening every year. Breast Self-Examination (BSE) is the one of the best methods for identifying breast cancer. Rural population has less access to medical facilities and their knowledge is low. Therefore, it is essential to educate them about breast cancer, its prevention and early detection. This study was aimed to assess the knowledge level offemales regarding breast cancer and breast self-examination. Materials \& Methods: Non experimental descriptive design was adopted for this study. 80 samples were selected th roug $h$ non probability sampling technique and the setting of the study was a rural community of Idukki district, Kerala. A structured knowledge questionnaire was used for data collection. Descriptive and inferential statistics were used to analyse the data. Results: Majority, $57.5 \%$ of samples were having an average level of knowledge, $27.5 \%$ of sa mples had good level of knowledge and $8.7 \%$ of samples had poor knowledge and $7.5 \%$ was found having excellent level of knowledge. A significant association was observed between the knowledge and education $\left(X^{2}=14.061, P 0.05=12.54\right)$, knowledge and income $\left(X^{2}=14.42, P 0.05=12.59\right)$ of women. But there was no association found between knowledge and other demographic variables.
\end{abstract}

Key Words: Breast Cancer, Breast Self-Examination, Knowledge, Booklet.

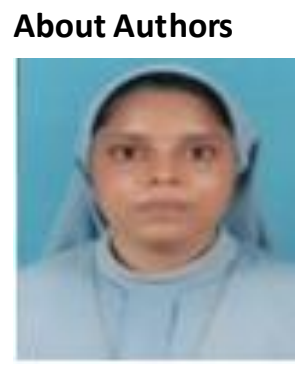

Author Ms Leena Mathew (Sr. Gladys Maria) is a Research Scholar in Himalayan University at Itanagar in Aru nachal Pradesh, India.

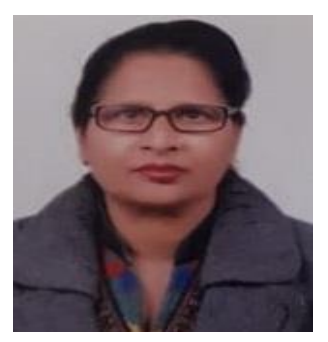

Author Dr. Bimla Rani is a Research Supervisor at Himalayan University in Itanagar, Arunachal Pradesh, India. She has presented papers in variousconferences and also has many publications to her name. 


\section{INTRODUCTION}

Women are the masterpiece creation of God and they pose high self-confidence as long as they are physicallyfit and healthy. They are dragged down by many illnesses; especially the ones that shatter their femininity. Breast c ancer is one of such events. It is the most common cancer among women. Increased fat intake, reduced exercise, obesity and reduced duration of breast feeding are some of the major casual factors. It attacks the women during the most productive years of life, but breast cancercan be cured with limited resources, if de tected earlier; but tre ating advanced stage disease is expensive and outcome is often poor. The most important strate gy for achieving e arly detection of breast cancer is mammography and physical examination of breast by a physician or a qualified he alth worker or clinical breast examination (CBE) and breast self-examination (BSE).

BSE is a process whe reby women examine their breast regularly to detect any abnormal swelling or lumps in order to seek prompt medical attention. It is the best way to note any changes in the breast, such as lu mp s or thickenings. Awareness on how to perform, when to perform and perceiving BSE are important and useful to detect breast cancer. Non-cancerous breast tumors are also abnormal growths, but it can increase the risk of getting breast cancer. Therefore, breast self-examination (BSE) itself helps to diagnose breast cancervery early.

Evidence suggests that if the examination is done properly and regularly, it may help to detect breast cancer e arly. It is an inexpensive risk-zero method of screening. It is used in an attempt to detect cancer and can be done at home. Even pregnant women can checktheir breast on monthly basis but women of all age s are encouraged to perfor $m$ breast self-examination at least monthly and to report to health care providers about the changes, immediately.

\section{NEED FOR THE STUDY}

Breast problems are significant health problems concerning women. It is the second most frequently occur ring cancer and the fifth most cause of cancer related mortality. According to WHO (2021), there were 2.3 million women diagnosed with breast cancer and 685000 deathsglobally in 2020. One in eight women develops cancer in her lifetime. Every 3 minutes, a woman is diagnosed with breast cancer and every 13 minute a woman dies.

According to NBCC 2021, it is estimated that 43,600 women and 530 men will die of breast cancer in the US on ly. In India as per GLOBOCAN 2018 data, there were approximately 162,468 new cases and 87,090 deaths occur ring annually due to breast cancer. Out of all cancers, breast cancer onlywas responsible for 1.5 lakh cases (10\%) of cancer in India by 2016. Breast cancer is the most common malignancy among the women in Kerala; it is about 30 to $35 \%$. According to the data available with the Thiruvananthapuram Cancer Registry, the prevalence rate in rural areas is 19.8 per 100,000, while in the urban areas, it is 30.5 per 100,000. According to the GBD report published in 2016, the burden of cancer in Kerala is $135.3 / 100,000$ of population in contrast to the national average of $100 / 100,000$ of population. The prevalence of any warning sign among the study population was 400/100,000 of population.

Approximately, $7 \%$ of women with breast cancer are diagnosed before the age of 40 years, and it is accounted for more than $40 \%$ of all cancer in women in this age group. Survival rates at this age group are worse when compared to older women. So, breast cancer in 'less than 40 age group' is also significant. So, a study regard ing the kn owledge about breast cancer and breast self-examination among females is significant. It may prevent the chance of its incidence in the future as well as reduce the occurrence rate.

\section{STATEMENT OF THE PROBLEM}

'A study to assess the knowledge regarding breast cancer and breast self-examination among females within a selected community of Idukki district in Kerala with a view to prepare an information booklet'

\section{OBJECTIVES}

1. To assess the level of knowledge of females regarding breast cancer and breast self-examination.

2. To determine the relationship of knowledge level of females about breast cancer and breast self-examination with their demographic variables. 


\section{ARTICLES}

3. Develop and provide an information booklet based on the level of knowledge regarding breast cancer and breast self-examination.

\section{RESEARCH METHODOLOGY}

- Research Design: Non experimental descriptive design was used.

- Research Approach: In this study, a quantitative research approach was considered.

- Setting: The present study was conducted at Kozhimala, a rural community of Idukki district of Kerala.

- Sample size: 80 females within the age group of 35-55 years were selected.

- Sampling technique: In this study, non-probability purposive sampling technique was used.

- Data collection tool:

Part I: Demographic data which consists of age, education, income, family history, parity and marital status.

Part II: It consists of 25 items of multiple-choice questions to assess the knowledge level of fe males regarding breast cancer and breast self-examination

- Data analysis: For data analysis, descriptive and inferential statistics were used

\section{RESULTS}

Section A: It deals with distribution of samples according to demographic variables

Table - 1: Frequency distribution of samples according to demographic variables

\begin{tabular}{|c|c|c|c|}
\hline \multirow{2}{*}{\multicolumn{2}{|c|}{ Variables }} & \multirow{3}{*}{$\begin{array}{c}\mathbf{f} \\
29\end{array}$} & \multirow{3}{*}{\begin{tabular}{|c|}
$\%$ \\
36.25
\end{tabular}} \\
\hline & & & \\
\hline \multirow[t]{4}{*}{ Age } & $35-40$ yrs. & & \\
\hline & $41-45$ yrs. & 18 & 22.50 \\
\hline & $46-50$ yrs. & 23 & 28.75 \\
\hline & $51-55$ yrs. & 10 & 12.50 \\
\hline \multirow[t]{3}{*}{ Education } & Primary & 0 & 0 \\
\hline & Secondary & 36 & 45.00 \\
\hline & University & 44 & 55.00 \\
\hline \multirow[t]{3}{*}{ Income (in Rupees) } & $\operatorname{Low}(<10,000)$ & 73 & 91.26 \\
\hline & Middle $(10,000-30,000)$ & 6 & 7.50 \\
\hline & High $(>30,000)$ & 1 & 1.20 \\
\hline \multirow[t]{2}{*}{ Family History } & Yes & 0 & 0 \\
\hline & No & 80 & 100.00 \\
\hline \multirow[t]{2}{*}{ Parity } & Nulliparous & 1 & 1.25 \\
\hline & Multiparous & 79 & 98.75 \\
\hline \multirow[t]{2}{*}{ Marital Status } & Single & 1 & 1.25 \\
\hline & Married & 79 & 98.75 \\
\hline
\end{tabular}




\section{ARTICLES}

Section - B: Distribution of samples according to knowledge level.

Table - 2: Frequency distribution of sample according to their level of knowledge $N=80$

\begin{tabular}{|l|c|c|c|c|}
\hline Knowledge Level & Score & Score in percentage & Frequency & Percentage \\
\hline Excellent & $20-25$ & $81-100$ & 6 & 7.5 \\
\hline Good & $15-19$ & $61-80$ & 22 & 27.5 \\
\hline Average & $10-14$ & $41-60$ & 46 & 57.5 \\
\hline Poor & $\leq 10$ & $\leq 40$ & 6 & 8.7 \\
\hline
\end{tabular}

Maximum score $=25$

\section{Knowledge level}

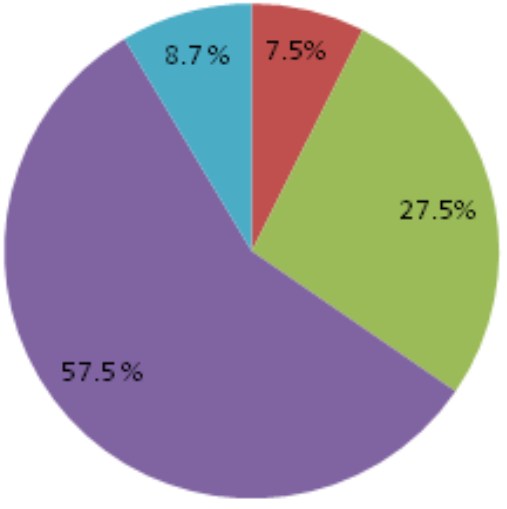

Excellent

a Good

- Average

a Poor

Figure - 1: Pie diagram representing distribution of sample according to knowledge level

Table -2 and pie diagram in Figure - 1 represent that 7.5\% sample had excellent knowledge, 27.5\% had good knowledge $57.5 \%$ had average knowledge and $8.7 \%$ had poor knowledge regarding breast cancer and breast selfexamination.

Section - C: Association between knowledge level of females and their selected demographic variables.

Table - 3: Association of level of knowledge and demographic variables

\begin{tabular}{|c|l|c|c|}
\hline SI. No. & Variables & Chi-square & P value \\
\hline 1. & Age & 7.0664 & 16.95 \\
\hline 2. & Education & 14.0610 & $12.54^{*}$ \\
\hline 3. & Family income & 14.4200 & $12.59^{*}$ \\
\hline 4. & Family history & 8.0340 & 9.49 \\
\hline 5. & Parity & 1.9800 & 7.85 \\
\hline 6. & Marital status & 2.1000 & 3.84 \\
\hline
\end{tabular}

$P<0.05$

* Significant 
DISCUSSION

Part - I: Distribution of samples based on demographic data

Demographic variables selected for this study were age, education, family income, family history, parity and ma rital status. $36.25 \%$ of samples belonged to 35-40 age group. More than half of them (55\%) had education at university level. $91.25 \%$ belonged to low-in c o m e group. None of the samples had family history of breast cancer. Majority of the samples (98.75\%) w ere married and mu I t i p a r o u s. Some of these findingswere consistent with another study wherein results showed that $38 \%$ of study population belonged to $31-40$ age group, $44 \%$ we re from lower middle class, majority of samples (80\%) were married and only few (7\%) hadbreast cancer in family history whereas educational status was contradicting with the present study result which showed that $30 \%$ had primary education (Rakesh Singh, Alka Turuk (2017). Another study was conducted in Himachal Pradesh and the result the re revealed that maximum women $42.5 \%$ were in the age group of $41-50$ years, $37.5 \%$ women were graduates, and the maximum number (87.5\%) of women was married, $82.5 \%$ of women had no history of breast cancer in family. Neha Kaushal et al (2017). This is congruent with the present study.

\section{Part II: level of knowledge on breast cancer and breast self-examination}

A cross-sectional study was carried out by Abdullah Nasser Alomair et al, (2020) among 422 female students at KSU. The study showed that the majority of participants, (57.4\%) had a moderate level of knowledge of breast cancer. Which is similar to present study result and it showed that $57.5 \%$ had average knowledge, $27.5 \%$ had good knowledge, $7.5 \%$ had excellent knowledge and $8.7 \%$ had poor knowledge regarding breast cance r and breast se Ifexamination. Another study which was conducted in Punjabamong adolescent girls revealed that $45 \%$ of adolescent girls had average knowledge and $45 \%$ of them had poor knowledge and onlya few (10\%) adolescent gir Is had good knowledge regarding breast Cancer (Amandeep Kaur2019). In a cross-sectional study conducted to assess the knowledge and attitude towards breast cancer among 414 nurses in hospital in Asmara, the result showed that $48.88 \%$ had a good knowledge regarding breast cancer and $32 \%$ knew at least one sign and symptom of breast cancer. (Amanuel Kidane Andegiorgishet al 2018)

\section{Part III: Association between level of knowledge and demographic variables}

The present study showed that there was significant association of knowledge with the selected demographic variables like education and income. However, other variables had no association. The above Punjab study also showed that there were significant relationships between knowledge and age, type of family, family's monthly income and source of health information $(p<0.05)$.

\section{CONCLUSION}

The present study was conducted to assess the knowledge regarding breast cancer and breast self-examination among females. Results revealed that majority of the samples (57.5\%) had average knowledge about breast cancer and BSE and only few (7.5\%) of them had excellent knowledge. It shows still there is a gap in information related to early detection and management about breast cancer. This indicates the importance of conducting a training programme to increase the level of awareness among the common people. So, the researcher developed an informational booklet regarding breast cancer and BSE.

\section{LIMITATIONS AND RECOMMENDATIONS}

- $\quad$ Since the sample was limited to 80, generalisation of findings was also limited

- A structured teaching programme could have been devised to improve their knowledge about breast cancer and BSE

- Health awareness programme can be performed in community setting

- Periodic training regarding BSE can be arranged in clinical settings especially in Gynaecology departments

- Mass media can play an important role for spreading information about breast cancer and BSE to improve awareness in the community. 


\section{REFERENCES}

1. Samira S Abo Al-Shiekh Mohammad Awadelkarim Ibrahim, Yasser S. Alajerami ‘Breast Cancer Knowledge and practice of Breast Self-Examination among Female University Students, Gaza" The scientific world jour nal, vol. 2021, Article ID6640324,7 pages, 2021. https:// doi.org/ 10.1115/2021/6640324

2. Mathew G, et al (2020) Community-based burden, warning signs, and risk factors of cancer using public - private partnership model in Kerala, India. J Family Med Prim Care 2020:9:745-50

3. J. Ferlay, M. Colombet, I. Soerjomataram et al., "Estimating the global cancer incidence and mortality in 2018: GLOBOCAN sources and methods," International Journal of Cancer, vol. 144, no. 8, pp. 1941-1953, 2019.

4. Abdullah Nasser Alomair et al, IJMDC. 2020; 4(2):429-434 doi:10.24911//IMMC.: 51-1576668182.

5. Love shah et al: A study about assessment of knowledge of breast cancer and breast self-examination : Ne pal journal of epidemiology.: 2019 June: 9(2):761-768From: https: // www.nchi.nlm.nih.gov.pmc.

6. Beulah Christy et al, (2019), A study to assess knowledge regarding breast cancer and breast self-examination, TNMC Journal of medical surgical nursing. Vol.7, issue page no: 15-18.

7. Kaur A. To assess the knowledge among adolescent girls regarding breast cancer: descriptive study. International Journal of Researchand Review. 2019; 6(8):70-76.

8. Bray F, Ferlay J, Soerjomataram I, Siegel RL, Torre LA, Jemal A. Global cancer statistics 2018: GLOBOCAN estimates of incidence and mortality worldwide for 36 cancers in 185 countries. CA Cancer J Clin 2018; 68:394424.

9. Rakesh Singh, Alka Turuk, A study to assess the knowledge regarding breast cancer and practices of Breast SelfExamination among women in urban area. International journal of community medicine and public health (abstract). 2017:18(6):1623-28.

From: http:// dx. doi.org./10.18203/2394-6040.jlcmph20174856.

10. Suwarna Madhukumaret al: Awareness about Breast Carcinoma and practice of Breast Self-Examination among basic science college students: Journal of family medicine and primary care (Abstract) 2017 july-sep: 6(3) :487490 From: https://www.ncbi.nlm.nib.gv.pmc.

11. Hemalatha Kumaraswamy et al: A study in determinants of awareness and practice of Breast Self-Examinatio $n$ among rural women in Trichy, Tamilnadu: Journal of midlife health. 2017April-June: 8(2) :84-88 From: https://pubmed.nchi.nlm.nih.gov.

12. MD Anuratha et al ;(2013) the nursing journal of India vol. 4, page no:228, 229. 